\title{
Effect of increased serum 25(OH)D and calcium on structure and function of post-menopausal women: a pilot study
}

\author{
H. J. Hillstrom ${ }^{1}$ (I) - R. Soeters ${ }^{1}$ - M. Miranda ${ }^{1}$ - S. I. Backus ${ }^{1}$ - J. Hafer ${ }^{2,1} \cdot$ M. Gibbons ${ }^{1}$ - I. Thaqi ${ }^{1}$ • M. Lenhoff ${ }^{1}$. \\ M. T. Hannan ${ }^{3} \cdot$ Y. Endo ${ }^{1} \cdot$ T. Sculco ${ }^{1} \cdot$ J. Lane $^{4}$
}

Received: 9 March 2020 / Accepted: 1 September 2020

(C) The Author(s) 2020, corrected publication 2021

\begin{abstract}
Summary The purpose was to determine if increasing serum 25(OH)D and calcium in postmenopausal women increased skeletal muscle size, strength, balance, and functional task performance while decreasing muscle fatigue. PCSA of the vastus lateralis increased and ascent of stairs time decreased after 6 months of increased serum 25(OH)D.

Purpose The Institute of Medicine recommends $\geq 20 \mathrm{ng} / \mathrm{ml}$ of serum 25-hydroxyvitamin D [25(OH)D] for bone and overall health. Serum 25(OH)D levels have been associated with physical performance, postural sway, and falls. The purpose of this study was to determine if increasing postmenopausal women's serum $25(\mathrm{OH}) \mathrm{D}$ levels from $20-30 \mathrm{ng} / \mathrm{ml}$ to $40-50 \mathrm{ng} / \mathrm{ml}$ improved skeletal muscle size, strength, balance, and functional performance while decreasing skeletal muscle fatigue.

Methods Twenty-six post-menopausal women (60-85 years old) with baseline serum 25(OH)D levels between $20 \mathrm{and} 30 \mathrm{ng} / \mathrm{ml}$ were recruited. Oral over-the-counter (OTC) vitamin D3 and calcium citrate were prescribed to increase subjects' serum 25(OH)D to levels between 40 and $50 \mathrm{ng} / \mathrm{ml}$, serum calcium levels above $9.2 \mathrm{mg} / \mathrm{dl}$, and PTH levels below $60 \mathrm{pg} / \mathrm{ml}$, which were confirmed at 6 and 12 weeks. Outcome measures assessed at baseline and 6 months included muscle physiological crosssectional area (PCSA), muscle strength, postural balance, time to perform functional tasks, and muscle fatigue. Repeated measures comparisons between baseline and follow-up were performed.

Results Nineteen subjects completed the study. One individual could not afford the time commitment for the repeated measures. Three individuals did not take their vitamin D as recommended. Two subjects were lost to follow-up (lack of interest), and one did not achieve targeted serum 25(OH)D. Vastus lateralis PCSA increased $(p=0.007)$ and ascent of stair time decreased $(p=$ 0.042 ) after 6 months of increasing serum $25(\mathrm{OH}) \mathrm{D}$ levels from $20-30 \mathrm{ng} / \mathrm{ml}$ to $40-50 \mathrm{ng} / \mathrm{ml}$. Isometric strength was unchanged. Anterior-posterior center of pressure (COP) excursion and COP path length decreased $(p<0.1)$ albeit non-significantly, suggesting balance may improve from increased serum 25(OH)D and calcium citrate levels.

Conclusions Several measures of muscle structure and function were sensitive to elevated serum 25(OH)D and calcium levels indicating that further investigation of this phenomenon in post-menopausal women is warranted.
\end{abstract}

Keywords Recommended serum 25(OH)D levels $\cdot$ Muscle cross-sectional area $\cdot$ Postural sway $\cdot$ Isometric strength $\cdot$ Muscle fatigue $\cdot$ Functional task times

H. J. Hillstrom

HillstromH@HSS.edu

1 Leon Root Motion Analysis Laboratory (LRMALab), Hospital for Special Surgery (HSS), 535 East 70th Street, New York, NY, USA

2 Biomechanics Lab, Department of Kinesiology, University of Massachusetts, Totman rm.110, 30 Eastman Lane, Amherst, MA, USA

3 Institute for Aging Research, Hebrew SeniorLife, Harvard Medical School, 1200 Centre Street, Boston, MA, USA

4 Metabolic Bone Disease Service, HSS, 535 East 70th Street, New York, NY, USA

\section{Introduction}

Serum 25(OH)D is widely acknowledged as the best measure of an individual's vitamin D status. The National Institutes of Health $(\mathrm{NIH})$ and Institute of Medicine (IOM) recommend $\geq 20 \mathrm{ng} / \mathrm{ml}$ of serum $25(\mathrm{OH}) \mathrm{D}$ for bone and overall health in healthy individuals (Table 1) $[1,2]$. Despite this recommendation, the definition of adequate serum 25(OH)D levels varies amongst investigators $(\geq 12.5 \mathrm{ng} / \mathrm{ml})[3](\geq 30 \mathrm{ng} / \mathrm{ml})[4]$ and professional organizations ((IOM [2] ( $\geq 20 \mathrm{ng} / \mathrm{ml})$, Vitamin D Task 
Table 1 IOM vitamin D recommendations

\begin{tabular}{|c|c|}
\hline $25(\mathrm{OH}) \mathrm{D} *$ & Health status \\
\hline$<12$ & $\begin{array}{l}\text { Associated with vitamin D deficiency, leading to rickets in infants } \\
\text { and children and osteomalacia in adults }\end{array}$ \\
\hline $12-20$ & $\begin{array}{l}\text { Generally considered inadequate for bone and overall health } \\
\text { in healthy individuals }\end{array}$ \\
\hline$\geq 20$ & $\begin{array}{l}\text { Generally considered adequate for bone and overall health } \\
\text { in healthy individuals }\end{array}$ \\
\hline$>50$ & $\begin{array}{l}\text { Emerging evidence links potential adverse effects to such high } \\
\text { levels, particularly }>60 \mathrm{ng} / \mathrm{ml}\end{array}$ \\
\hline
\end{tabular}

*Serum concentrations of $25(\mathrm{OH}) \mathrm{D}$ are reported in nanograms per milliliter $(\mathrm{ng} / \mathrm{ml})$
Force [5] (40-80 ng/ml), and the Endocrine Society [6] $(30-100 \mathrm{ng} / \mathrm{ml}))$.

\section{Purported vitamin D effects upon muscle strength, balance, and falling}

Maintaining sufficient serum 25(OH)D (30-60 ng/ml) has been associated with benefits to musculoskeletal health, muscle strength [7-9], balance [10], and decreased risk of falls. Vitamin D deficiency has been associated with sarcopenia [11], reduced physical activity [8, 10-12], increased risk for falls [10], and fall-related fractures in older adults [13]. A direct link has been suggested between vitamin $\mathrm{D}$ and physical performance in community dwelling older adults [14]. Increasing serum $25(\mathrm{OH}) \mathrm{D}$ has also resulted in no change in physical performance in several studies $[15,16]$. The disparity in conclusion is, in part, a result of variations in thresholds for adequate vitamin $\mathrm{D}$, subject inclusion criteria, and outcome measurements. Still, a meta-analysis of 26 randomized controlled trials demonstrated the benefit of vitamin $\mathrm{D}$ along with calcium supplementation in prevention of falls in elderly women [17].

\section{Vitamin D toxicity}

Acute toxicity from vitamin D supplementation is rare and consists principally of acute hypercalcemia, which results from doses that exceed 10,000 IU per day; associated serum levels of 25(OH)D were well above $150 \mathrm{ng} / \mathrm{ml}$ [13]. Chronically elevated 25(OH)D over $40-45 \mathrm{ng} / \mathrm{ml}$ has been associated with increased falls risk [18]. In this study, the targeted serum $25(\mathrm{OH}) \mathrm{D}$ of $40-50 \mathrm{ng} / \mathrm{ml}$ is below what is considered toxic.

These features of $25(\mathrm{OH}) \mathrm{D}$ appear to support a link between supplementation in older persons, but a gap in knowledge exists as to whether increasing baseline $25(\mathrm{OH}) \mathrm{D}$ to 40 $50 \mathrm{ng} / \mathrm{ml}$ in women who are insufficient will have measurable effects on common muscle outcomes, especially so in postmenopausal women who are at higher risk for falls, fractures, and other musculoskeletal outcomes. Thus, we examined the ability to increase serum levels of $25(\mathrm{OH}) \mathrm{D}$ to $40-50 \mathrm{ng} / \mathrm{ml}$ in a sample of post-menopausal women and the 6-month effects upon key muscle and function outcomes.

The central hypothesis was that increasing serum $25(\mathrm{OH}) \mathrm{D}$ from $20-30 \mathrm{ng} / \mathrm{ml}$ to $40-50 \mathrm{ng} / \mathrm{ml}$ will increase muscle strength, reduce muscle fatigue as measured by EMG, enhance balance, and improve physical function in postmenopausal women.

\section{Methods}

\section{Study population}

Twenty-six post-menopausal women with baseline serum 25(OH)D levels between 20 and $30 \mathrm{ng} / \mathrm{ml}$ who were candidates for oral vitamin $\mathrm{D}$ supplementation were recruited for participation from the patients of a metabolic bone disease specialist (author J.L.). The inclusion criteria for enrollment were postmenopausal women (defined by absent menarche for at least 1 year), aged 60 to 85 years, able to walk 2 blocks and climb 2 flights of stairs without assistive devices (community ambulators), able to follow simple instructions, and able to perform single leg standing for 3 or more seconds. At the time of enrollment, the following serum levels were required: vitamin D levels between 20 and $30 \mathrm{ng} / \mathrm{ml}$, calcium levels above $9.2 \mathrm{mg} / \mathrm{dl}$, and PTH levels below $60 \mathrm{pg} / \mathrm{ml}$. All participants had a bone mineral density measured T-score of 1.5 or better in the spine or femur. Study participants were excluded if they had current or previous neurological diagnoses that affected ambulation, current or previous diagnosis of moderate to severe spinal deformity (i.e., scoliosis), limb length inequality greater than $2 \mathrm{~cm}$, sarcoidosis, active cancer, a history of kidney stone or renal impairment, irritable bowel syndrome, past bariatric surgery, celiac sprue disease, primary hyperparathyroidism, current or previous diagnosis of metabolic bone disease other than postmenopausal osteoporosis, or received anti-osteoporotic agents with anabolic effects (e.g., estrogen, or selective estrogen receptor modulators (SERMs)), during the past 12 months. Although estrogen and SERMS 
have different mechanisms of actions, both drugs could affect muscle strength, we excluded individuals on agents other than bisphosphonates or teriparatide to avoid confounding variables and ensure the homogeneity of the study population. Subjects were excluded if they were in a formal lower extremity strength training program (i.e., physical therapy, personal training). One subject was excluded from the analysis since the target serum 25(OH)D level of $40-50 \mathrm{ng} / \mathrm{ml}$ was not reached at 12 weeks.

\section{Study design and testing protocol}

This pilot investigation was a prospective cohort design with repeated measurements comprised of baseline and 6-month follow-up once the target serum 25(OH)D levels were obtained (Fig. 1). This study received Institutional Review Board approval for human subject assurance at the Hospital for Special Surgery (HSS), and all subjects provided signed informed consent. Dual-energy X-ray absorptiometry (DEXA) scans were performed at baseline as a screening tool to ensure that lumbar spine and femoral neck T-score inclusion criteria were met. At baseline, serum 25(OH)D levels were assessed for each participant. Vitamin D3 and calcium citrate supplementation were prescribed by a metabolic bone disease specialist (author J.L.) to bring serum 25(OH)D levels to 40-50 $\mathrm{ng} / \mathrm{ml}$ and serum calcium to $9.2 \mathrm{mg} / \mathrm{dl}$ or greater. Strength, balance, functional task performance, and muscle fatigue were obtained pre-vitamin D supplementation and measured in the Leon Root, MD Motion Analysis Laboratory (LRMALab) at HSS. Physiological cross-sectional area (PCSA) of relevant musculature (vastus lateralis and semimembranosus) was assessed in the Radiology Department at HSS.

Serum 25(OH)D was measured at the HSS laboratory for medicine at baseline. The Abbott Architect Immunochemistry Analyzer was used to perform the ARCHITECT 25-OH vitamin D Assay which was standardized against NIST SRM 2972 (National Institute of Standards Reference Material
2972). The performance specifications for the test were (1) the total coefficient of variation $(\mathrm{CV}<5 \%)$ and (2) the mean bias $=-17.4 \%$ for vitamin $\mathrm{D}$ insufficient and $-8.9 \%$ for vitamin D supplemented subjects [19].

Serum 25(OH)D levels were repeated at 6 weeks and 12 weeks at a laboratory of convenience for the patient with adjustments in over-the-counter (OTC) vitamin D3 (cholecalciferol) dosage made if the target levels were not between 40 and $50 \mathrm{ng} / \mathrm{ml}$. All outside laboratories are part of the network used for routine clinical practice. When target serum 25(OH)D levels were reached, follow-up testing was scheduled 6 months later. The 6-month follow-up data collection replicated all baseline measurements.

Subjects were monitored every 6 weeks as per routine clinical protocol to ensure serum $25(\mathrm{OH}) \mathrm{D}$ levels did not exceed $50 \mathrm{ng} / \mathrm{ml}$. All patients were thoroughly screened for potential risk for vitamin D-related toxicity; no patient exceeded serum 25(OH)D levels greater than $50 \mathrm{ng} / \mathrm{ml}$, demonstrated adverse effects, or indicated hypersensitivity.

The goal of the oral OTC vitamin D and calcium supplementation was to increase the serum $25(\mathrm{OH}) \mathrm{D}$ from $20-30$ $\mathrm{ng} / \mathrm{ml}$ to $40-50 \mathrm{ng} / \mathrm{ml}$. Calcium supplementation of $500 \mathrm{mg}$ to $1000 \mathrm{mg}$ was typically required to achieve this goal and included as part of the clinical standard of care for this population.

\section{Study hypotheses}

The following hypotheses were tested in the investigation:

H1: After 6 months of oral vitamin D administration, muscle strength (isometric knee extension and flexion torque) and muscle structure (vastus lateralis and semimembranosus physiological cross-sectional area (PCSA)) will increase, while muscle fatigue (electromyography (EMG) median frequency shift) will decrease
Fig. 1 Vitamin D protocolBaseline and 6 months after achieving target serum $25(\mathrm{OH}) \mathrm{D}$ levels

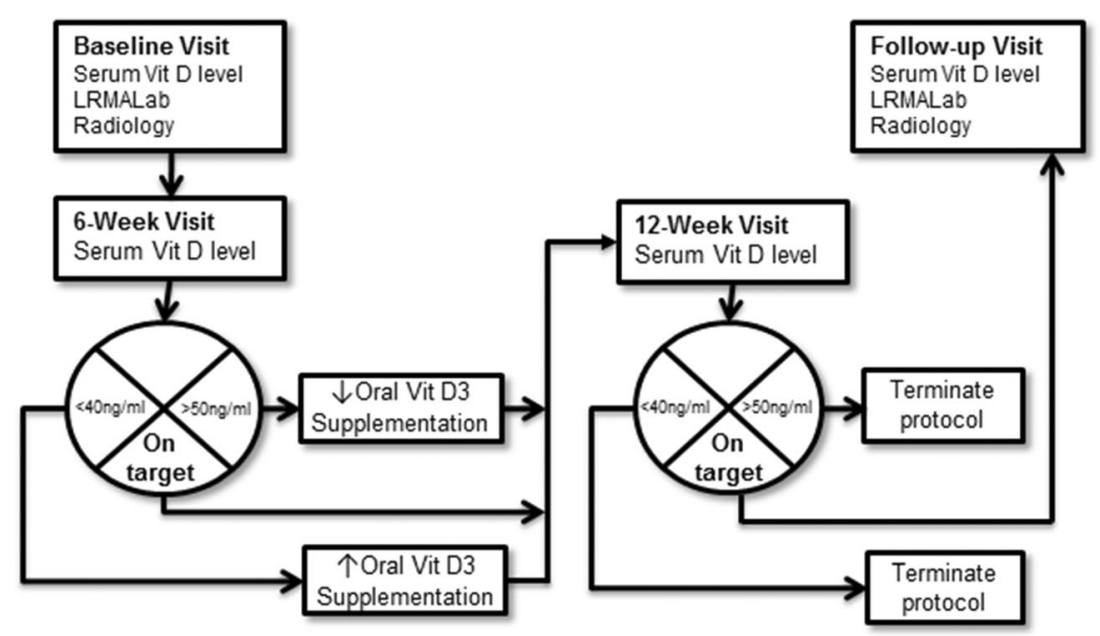


compared with the baseline as an indicator of improved muscle function.

H2: After 6 months of oral vitamin D administration, postural sway area will decrease during both single and bipedal stances compared with the baseline as an indicator of improved balance.

H3: After 6 months of oral vitamin D administration, functional task performance times will decrease when compared with the baseline as an indicator of improved functional performance.

\section{Baseline visit testing procedure}

\section{LRMALab}

Demographics were collected at enrollment. At baseline, participants performed (1) bipedal and single leg postural stabilograms to study balance, (2) timed measures of functional tasks to assess performance, (3) maximum voluntary isometric contraction (MVIC) knee flexion and extension torque testing to assess strength, and (4) surface EMGs during a sustained sub-MVIC to determine muscle fatigue.

(1) Postural stabilogram: To evaluate bipedal posture during quiet standing, bilateral plantar pressures were acquired while subjects stood with their feet at a self-selected angle and base of support upon an emed-X (Novel, Munich, Germany). With arms to both sides looking straight ahead, the subject stood for $60 \mathrm{~s}$ (Fig. 2, left) for three trials. For single leg postural stabilogram, subjects then stood on their self-reported dominant limb (the one they would use to kick a soccer ball) (Fig. 2, right) for $30 \mathrm{~s}$. If the subject was unable to maintain postural stability for the duration of the trial, then the data was analyzed for the time that they were able to maintain stability. The center of pressure (COP) maximum excursion was determined in the anterior-posterior $\left(\mathrm{COP}_{\mathrm{AP}}\right)$ and medial-lateral $\left(\mathrm{COP}_{\mathrm{ML}}\right)$ directions. To calculate the sway area $\left(\mathrm{SWAY}_{\mathrm{AREA}}\left(\mathrm{cm}^{2}\right)\right)$, a $95 \%$ confidence interval ellipse was fit to the COP trajectory.

(2) Timed functional tasks: We recorded the time taken to complete each of three functional tasks: timed up and go (TUG), walking 50' on a straight and level course at a comfortable speed, and ascent of 10 steps (rails were available if subjects needed to use them) [20]. The TUG test began with the participant seated in a chair with arms. The participant was instructed "When I say go...", (1) stand up from the chair, (2) walk to the line on the floor (10' from the chair) at your normal pace, (3) turn, (4) walk back to the chair at your normal pace. and (5) sit down again.

(3) Dynamometry: bilateral isometric strength testing of the knee extensor and flexor muscles was performed using an isokinetic dynamometer (Biodex System 4, Biodex Medical Systems, Shirley, NY). The subject sat on the testing bench with hips in $80^{\circ}$ of flexion; back supported in a comfortable position; and pelvis stabilized with a waist belt according to the standard operating procedures for knee isometric testing. An additional padded stabilization strap was placed over the anterior aspect of the thigh. Isometric testing was completed at $30^{\circ}$ and $60^{\circ}$ of knee flexion. Three 5-s trials of maximal effort were collected with a 10 -s rest between trials, a 20 -s rest between positions, and a 2 min rest period between sides. MVIC strength of the knee extensors and flexors was defined as the peak torque $(\mathrm{Nm})$ across the three trials.

(4) EMG testing: Before isokinetic dynamometry, surface EMG electrodes were applied according to standard clinical testing protocol as follows: the skin was prepared with isopropyl alcohol to reduce impedance. EMG surface electrode preamplifiers were placed on the vastus lateralis and vastus medialis according to SENIAM guidelines and confirmed on a real-time digital display [21]. EMG data was acquired during a MVIC while making the dynamometry measurements. After a 2-min rest following the MVIC, and in the same position, seated on the isokinetic dynamometer, subjects performed a sustained isometric knee extension contraction at 50\% of MVIC. Subjects were given visual feedback (a realtime bar graph on a computer monitor with a target line) and verbal cues from the tester (i.e., "kick harder," "hold it steady at that level") to help them maintain a knee torque that was 50\% MVIC [22]. This contraction was maintained for $1 \mathrm{~min}$. If the subject could not sustain the $50 \%$ MVIC for $1 \mathrm{~min}$, then their best effort was recorded for the duration of the trial. The raw EMG data was divided into $250 \mathrm{~ms}$ time segments. Each segment was transformed into the frequency domain and the median power frequency for each segment calculated. The median power frequency values were plotted versus time and a linear regression calculated. The steeper the line (i.e., more negative the slope), the greater the rate of fatigue.

\section{Radiology department}

DXA measurements were taken prior to enrollment as part of the standard of care of the metabolic bone disease specialist (J.L.) who recruited each subject for this study. DXA measurements served as a screening tool to ensure that all 
Fig. 2 Bipedal postural stabilogram (left) and single leg postural stabilogram (right)

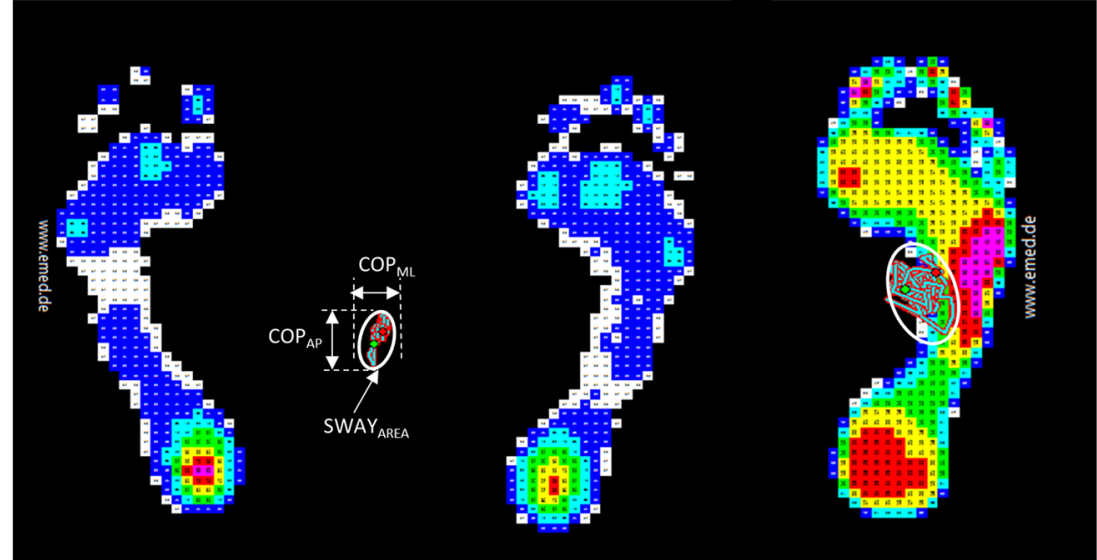

participants had a bone mineral density measured T-score of 1.5 or better in the spine or femur.

Ultrasound A board-certified radiologist at HSS with subspecialty expertise in musculoskeletal ultrasound (author Y.E.) assessed each subject's vastus lateralis and semimembranosus PCSA $\left(\mathrm{cm}^{2}\right)$ with ultrasound using an iU22 scanner (Philips Healthcare) with a $9 \mathrm{MHz}$ linear transducer [23]. First, with the subject seated and knees flexed to $90^{\circ}$, the PCSA of the right and left vastus lateralis was measured after visually approximating the mid femur (mid-thigh) level. This was repeated twice and the average of the three PCSA measurements was used to minimize the subjectivity associated with identifying the mid femur location. Next, with the subject prone and hips and knees extended, the PCSA of the bilateral semimembranosus was measured after visually approximating the mid femur level. Again, this was repeated twice and the average of the three measurements was recorded for each side. All ultrasound measurements were scheduled to immediately follow LRMALab testing and conducted within the department of radiology of HSS.

\section{Oral vitamin D supplementation}

After baseline testing was performed, the subject began oral vitamin D3 supplementation to achieve target serum $25(\mathrm{OH}) \mathrm{D}$ levels between 40 and $50 \mathrm{ng} / \mathrm{ml}$. Vitamin D was prescribed by our metabolic bone disease specialist (author J.L.). If the patient's serum $25(\mathrm{OH}) \mathrm{D}$ was at $20 \mathrm{ng} / \mathrm{ml}$, they were prescribed 4000 IU. Initial dosage was individually determined based upon the subject's baseline serum $25(\mathrm{OH}) \mathrm{D}$ levels. Oral vitamin D3 was dosed at either 1000, 2000, 3000, or 4000 IU daily, standard dosing units. Dosage was $\leq 4000$ IU/day for 6 weeks to achieve target serum 25(OH)D levels between 40 and $50 \mathrm{ng} / \mathrm{ml}$. At 6 weeks the patient's serum $25(\mathrm{OH}) \mathrm{D}$ level was retested. In general, $2000 \mathrm{IU}$ to $3000 \mathrm{IU}$ per day was required to maintain a level between 40 and 50 $\mathrm{ng} / \mathrm{ml}$ (i.e., the target range) for 6 months. Subjects received calcium citrate supplementation from standard over-thecounter sources. Patients were prescribed $500 \mathrm{mg}$ daily if dairy was part of their diet and $1000 \mathrm{mg}$ if not. Calcium citrate dosage was adjusted to achieve and maintain serum calcium levels above $9.2 \mathrm{mg} / \mathrm{dl}$ and PTH levels below $60 \mathrm{pg} / \mathrm{ml}$. Serum PTH level was monitored.

Six weeks after initiating vitamin D and calcium supplementation, each subject was required to obtain another serum analysis to adjust their supplementation doses. Target levels of serum 25(OH)D (40-50 ng/ml), calcium above $9.2 \mathrm{mg} / \mathrm{dl}$, and PTH below $60 \mathrm{pg} / \mathrm{mL}$ were maintained with appropriately adjusted doses. Laboratory results were ordered and archived by the Metabolic Bone Disease Clinic of HSS. Subjects who did not achieve the target $25(\mathrm{OH}) \mathrm{D}$ level by the 12 -week blood test were terminated. Subjects were informed regarding any required changes in vitamin D3 dose by phone and by study physicians. The last periodic check was performed at 3 months since vitamin D has a half-life from 4 to 8 weeks. Note that only one subject did not achieve the target $25(\mathrm{OH}) \mathrm{D}$ level by the 12 -week blood test.

\section{Follow-up visit_LRMALab and radiology department}

Six months after each subject had reached the target serum $25(\mathrm{OH}) \mathrm{D}$ level of $40-50 \mathrm{ng} / \mathrm{ml}$, follow-up visits at the LRMALab and the radiology departments of HSS were performed. The same testing protocol used at baseline was repeated.

\section{Statistical analysis}

The primary outcomes were as follows: (1) strength (peak torque during MVIC) defined as the maximum torque during isometric contraction in any one of the three trials of knee extension and flexion as measured on the Biodex dynamometer); (2) muscle area (vastus lateralis and semimembranosus PCSA $\left(\mathrm{cm}^{2}\right)$, defined as an ultrasound based measure of the muscle diameter at multiple levels along 
the length of the thigh, serving as an estimate of muscle force); (3) muscle fatigue (median frequency of the vastus lateralis and semimembranosus muscle EMGs during a 50\% MVIC defined as the frequency where half the power is above and half the power is below); (4) balance (postural sway area

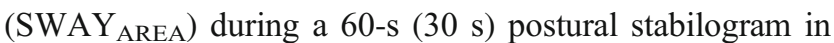
bipedal (single leg) stance defined as the area of a best elliptical fit to center of pressure (COP) sway at the 95\% confidence interval); and (5) functional performance (the time in seconds taken to complete each of three functional tasks (rising from a 42-cm chair height, walking 50' at a comfortable speed, and ascent and descent of 10 steps)).

The secondary outcomes were (1) balance (anterior-posterior and medial-lateral maximum $\left(C O P_{A P}, C O P_{M L}\right)$ sway for single and bipedal stance, single leg stance time).

Data analysis included descriptive statistics (means, standard deviations, coefficient of variation) for all primary and secondary outcome variables collected at baseline and after 6 months of achieving target $25(\mathrm{OH}) \mathrm{D}$ levels. Each outcome variable was tested for normality (Wilks-Shapiro, Q-Q plots) and homogeneity of variance (Levine's test). Comparative statistics were employed to test each hypothesis. Primary and secondary outcome variables were compared pre- and post-treatment protocol using a generalized estimation equation (GEE)-based model for bilateral data to account for potential dependence between limbs or repeated measures analysis of covariance (ANCOVA) across time (baseline and 6month follow-up). A $p$ value $\leq 0.05$ was set for statistical significance. A $p$ value $\leq 0.10$ was set for identifying parameters of interest for future investigation (borderline statistical significance). All data analysis was conducted by using SPSS software (version 19.0).

\section{Results}

\section{Study population}

Twenty-six post-menopausal women met inclusion/exclusion criteria and were enrolled in the study. Seven participants were lost to follow-up (unrelated medical conditions, did not answer phone for scheduling, missed follow-up appointment, and could not reschedule), and one subject was unable to achieve the target vitamin D level by 12 weeks. Nineteen subjects completed baseline and follow-up testing. Of these participants, age (mean \pm SD) was $70.1 \pm 9.2$ years, body weight was $58.8 \pm 10.9 \mathrm{~kg}$, height was $160.7 \pm 6.1 \mathrm{~cm}$, and body mass index (BMI) of $22.9 \pm 4.6 \mathrm{~kg} / \mathrm{m}^{2}$. The T-scores at the lumbar spine was $-1.18 \pm 1.6$ and at femoral neck was $1.87 \pm 0.8$. Seventeen participants were white, 1 black, and 1 Asian with all but three participants being right limb dominant. One subject was unable to obtain the 6-month ultrasound measures. Table 2 summarizes the effect of elevating serum
25(OH)D levels from $20-30 \mathrm{ng} / \mathrm{ml}$ to $40-50 \mathrm{ng} / \mathrm{ml}$ upon differences in muscle structure, strength, and fatigue. The PCSA $\left(\mathrm{cm}^{2}\right)$ significantly increased $(p<0.05)$ for the vastus lateralis but not for the semimembranosus after 6 months of elevated serum $25(\mathrm{OH}) \mathrm{D}$ levels. Muscle strength and fatigue were unchanged.

Table 3 lists the effect of elevating serum 25(OH)D levels upon balance, functional tasks, and endurance between baseline $\left(\right.$ Visit $\left._{1}\right)$ and follow-up (Visit 2$)$. During bipedal posture, anterior-posterior (AP) center of pressure (COP) excursion and center of pressure path length were different $(p<0.1)$ over follow-up. One leg postural stabilogram parameters over 6months were not significantly changed following increased serum $25(\mathrm{OH}) \mathrm{D}$. The coefficient of variation $(\mathrm{S} / \mathrm{X})$ in bipedal elliptical sway reduced from $120 \%$ to $54 \%$ and in one leg elliptical sway from $92 \%$ to $65 \%$. These changes in postural sway and COP excursion are indicative of improved balance. The 10-stair ascent time was significantly reduced after increased serum $25(\mathrm{OH}) \mathrm{D}$ levels. The TUG and 50' walk times were not significantly changed after 6 months. Endurance as measured by single limb stance times was not significantly changed as well.

A post hoc power analysis was performed. The achieved power based upon effect sizes observed for each outcome measure is shown in Tables 2 and 3. The sample size required for the observed effect size, $\alpha<0.05$, and power $>0.8$ was computed for each outcome measure. Seven of sixteen outcome measures would be properly powered with an $N=148$.

\section{Discussion}

Physiological cross-sectional area (PCSA), a measure of gross muscle structure, increased in the vastus lateralis after increasing serum 25(OH)D levels from 20-30 ng/ml to $40-50 \mathrm{ng} / \mathrm{ml}$. Although this did not translate into an increase in knee extension moment, there was a functional improvement in the time required to ascend 10 stairs. This change in muscle structure provided partial support for hypothesis 1 . Muscle fatigue and bipedal and one leg postural stabilogram parameters did not significantly change after increased levels of serum 25(OH)D. In this small group, AP COP excursion and path length demonstrated a trend for reduction and may hold promise in a larger sample. Coefficient of variation for elliptical SWAY $_{\text {AREA }}$ during bipedal and one leg postural sway was also reduced, so hypothesis 2 was partially supported. Time for ascent of 10 stairs was significantly reduced and provided partial support for hypothesis 3 of this study.

Our study focused upon increasing serum $25(\mathrm{OH}) \mathrm{D}$ from what the IOM considers adequate $(20-30 \mathrm{ng} / \mathrm{ml})$ to $40-50$ $\mathrm{ng} / \mathrm{ml}$. Results from our study differ compared with the literature based upon serum 25(OH)D levels studied. For example, Cangussu et al, reported post-menopausal women receiving 
Table 2 Baseline and follow-up measures of muscle structure, fatigue, and strength

\begin{tabular}{|c|c|c|c|c|c|c|c|c|c|c|}
\hline$N=19$ & $\mathrm{~N}_{\text {sub }}$ & $\mathrm{N}_{\text {limbs }}$ & $\mathrm{V}_{1}$ & $\mathrm{SD} \mathrm{V}_{1}$ & $\mathrm{~V}_{2}$ & $\mathrm{SD} \mathrm{V} \mathrm{V}_{2}$ & $\chi^{2}$ & $p$ value & *Power & ${ }^{\wedge} N(\alpha<0.05 ; p>0.8)$ \\
\hline \multicolumn{11}{|l|}{$\operatorname{PCSA}\left(\mathrm{cm}^{2}\right)$} \\
\hline Vastus lateralis $\left(\mathrm{cm}^{2}\right)$ & 18 & 36 & 10.9 & 3.4 & 12.4 & 3.7 & 7.40 & 0.007 & 0.82 & 37 \\
\hline Semimembranosus $\left(\mathrm{cm}^{2}\right)$ & 18 & 36 & 7.0 & 1.7 & 7.1 & 1.3 & 0.074 & 0.785 & 0.103 & 1467 \\
\hline \multicolumn{11}{|c|}{$\mathrm{EMG}-$ muscle fatigue $(\mathrm{Hz} / \mathrm{s})$} \\
\hline Quadriceps slope (Hz/s) & 19 & 38 & -0.1 & 0.1 & -0.1 & 0.1 & 1.16 & 0.281 & 0.05 & \\
\hline Hamstring slope (Hz/s) & 19 & 38 & -0.2 & 0.2 & -0.2 & 0.3 & 0.092 & 0.761 & 0.05 & \\
\hline \multicolumn{11}{|l|}{ Isometric strength (Nm) } \\
\hline Knee extension (Nm) & 19 & 38 & 108.6 & 30.4 & 105.8 & 27.0 & 0.268 & 0.605 & 0.145 & 658 \\
\hline Knee flexion (Nm) & 19 & 38 & 52.9 & 15.6 & 51.2 & 11.1 & 0.68 & 0.410 & 0.18 & 416 \\
\hline
\end{tabular}

* Power 1- $\beta$ achieved post hoc, ${ }^{\wedge} N$ sample size required for effect size achieved, and $\alpha<0.05 ; p>0.8$

vitamin D3 orally had a significant increase in lower limb muscle strength $(25.3 \%)$ as measured by the chair rising test while those in the placebo group lost lean muscle mass [7]. This study raised serum $25(\mathrm{OH}) \mathrm{D}$ in the treatment group from 15.0 to $27.5 \mathrm{ng} / \mathrm{ml}$, which was lower than the baseline level included in our current study. Their inclusion of individuals with a lower baseline of serum 25(OH)D may have resulted in greater room for lower limb muscle strength improvement compared with our study.

Iolascon et al (2015) evaluated 80 post-menopausal women [24] and found that those women with serum 25(OH)D levels $>30 \mathrm{ng} / \mathrm{ml}$ had increased handgrip strength, knee extension strength, 4-m gait speed, and improved short physical performance battery compared with the hypovitaminosis group (serum $25(\mathrm{OH}) \mathrm{D}$ levels $<30 \mathrm{ng} / \mathrm{ml})$ [24]. Although in our subjects, knee extension strength was unchanged, we were able to demonstrate a larger PCSA for the vastus lateralis and improved 10 step stair ascent time suggesting improved quadriceps structure and function.

Mathei et al (2013) studied 367 individuals over 80 years old to determine the prevalence of vitamin D deficiency ( 20 $\mathrm{ng} / \mathrm{ml})$, insufficiency $(10-19 \mathrm{ng} / \mathrm{ml})$, and severe insufficiency $(<10 \mathrm{ng} / \mathrm{ml})$ and found no relation between balance, gait speed, and grip strength [25]. It is possible that once vitamin D levels were inadequate, stratification across levels of physical performance was more difficult to observe [25]. Taken together, the differences in protocol designs, age of subjects, and stratification by different serum $25(\mathrm{OH}) \mathrm{D}$ levels may in part explain the differences in outcomes reported in the literature compared with our study.
Table 3 summary of vitamin D study effects upon balance, activities of daily living, and endurance

\begin{tabular}{|c|c|c|c|c|c|c|c|c|c|}
\hline$N=19$ & $\mathrm{~N}$ & $\mathrm{~V}_{1}$ & $\begin{array}{l}\text { SD } \\
V_{1}\end{array}$ & $\mathrm{~V}_{2}$ & $\begin{array}{l}\mathrm{SD} \\
\mathrm{V}_{2}\end{array}$ & $\mathrm{~F}$ & $\begin{array}{l}p \\
\text { value }\end{array}$ & ${ }^{*}$ Power & $\begin{array}{l}{ }^{\wedge}(\alpha< \\
0.05 ; P> \\
0.8)\end{array}$ \\
\hline \multicolumn{10}{|l|}{ Balance_-bipedal } \\
\hline $\begin{array}{l}\text { Elliptical sway area } \\
\left(\mathrm{cm}^{2}\right)\end{array}$ & 19 & 3.0 & 3.6 & 1.9 & 1.0 & 1.84 & 0.191 & 0.416 & 55 \\
\hline $\mathrm{AP}$ excursion $(\mathrm{cm})$ & 19 & 2.3 & 1.1 & 1.7 & 1.0 & 3.403 & 0.082 & 0.771 & 21 \\
\hline Path length (cm) & 19 & 60.4 & 22.5 & 52.4 & 12.7 & 3.617 & 0.073 & 0.528 & 39 \\
\hline \multicolumn{10}{|l|}{ Balance-single leg } \\
\hline $\begin{array}{l}\text { Elliptical sway area } \\
\left(\mathrm{cm}^{2}\right)\end{array}$ & 19 & 24.2 & 22.3 & 19.4 & 12.7 & 1.919 & 0.183 & 0.272 & 103 \\
\hline AP excursion $(\mathrm{cm})$ & 19 & 7.0 & 5.0 & 6.1 & 3.1 & 0.906 & 0.354 & 0.217 & 148 \\
\hline Path length (cm) & 19 & 78.2 & 56.3 & 83.1 & 45.2 & 0.240 & 0.629 & 0.106 & 689 \\
\hline $\begin{array}{l}\text { Single limb stance time } \\
\quad(\mathrm{sec}) \\
\text { Functional tasks ( } \mathrm{sec})\end{array}$ & 19 & 15.7 & 9.1 & 16.9 & 9.7 & 0.644 & 0.433 & 0.133 & 382 \\
\hline $\begin{array}{l}\text { Timed up and go (TUG) } \\
(\mathrm{sec})\end{array}$ & 19 & 13.9 & 2.5 & 13.9 & 2.8 & 0.00 & 0.994 & 0.05 & \\
\hline 50’ walk (sec) & 19 & 12.6 & 2.3 & 12.8 & 2.4 & 0.175 & 0.681 & 0.098 & 857 \\
\hline 10 stair ascent $(\mathrm{sec})$ & 19 & 7.0 & 3.0 & 5.8 & 1.2 & 4.773 & 0.042 & 0.609 & 31 \\
\hline
\end{tabular}

${ }^{*}$ Power $1-\beta$ achieved post hoc, ${ }^{\wedge} N$ sample size required for effect size achieved, and $\alpha<0.05 ; P>0.8$ 
In a 2017 meta-analysis $(n=2866)$, no change in strength due to higher $25(\mathrm{OH}) \mathrm{D}$ levels was reported but the TUG significantly reduced (improved) [26]. Similarly, the subjects in our study had no improvement in strength following higher 25(OH)D levels. Although the TUG was unchanged, another functional performance measure (stair ascent time) improved. Perhaps this was related to the need for a combination of increased strength and balance to complete the higher demand task of stairs rather than the requirements to perform quiet standing or TUG test.

In a 4-week study of vitamin D supplementation in postmenopausal women, balance significantly improved [27]. Saito et al. randomly assigned 50 post-menopausal women with osteoporosis to receive vitamin D supplement and bisphosphonates or bisphosphonates only [28] and found, at 6 months, no changes in the control group, while the vitamin D group's back extensor and iliopsoas muscle strength as well as functional performance (TUG test and dynamic sitting balance) significantly increased. We found that AP COP excursion and the COP path length showed a trend for reduction after 6-months of elevated serum 25(OH)D $(p<0.1)$, suggesting balance may improve after vitamin $\mathrm{D}$ supplementation.

Furthermore, low serum 25(OH)D levels $(<10 \mathrm{ng} / \mathrm{ml})$ have been linked to a higher risk of repeated falling [14, 29-31]. Vitamin D supplementation in vitamin D-deficient older adults results in a reduction in falls [12, 31-35]. Metaanalysis of five randomized controlled trials has shown that vitamin D supplementation of $\geq 700$ IU resulted in decreased risk of falls by $22 \%$ [36]. In addition, meta-analysis of 26 randomized controlled trials demonstrated the benefit of vitamin D along with calcium supplementation in prevention of falls in elderly women [17].

Increased body sway, higher risk of falls, and fall-related fractures are linked with hypovitaminosis D [37]. When vitamin D-deficient $(\leq 12 \mathrm{ng} / \mathrm{ml})$ individuals with a history of falls were treated with intramuscular injection of 600,000 IU of vitamin $\mathrm{D}_{2}$, subjects showed improved performance, reaction time, and balance, but not muscle strength after 6 months [32]. Although evidence demonstrates a positive association between serum $25(\mathrm{OH}) \mathrm{D}$ and balance along with muscle fiber distribution and strength, the minimum requirement for improving these parameters and prevention of falls remains controversial. The clinical implications of enhanced balance and reduced muscle fatigue may decrease the number of falls and fractures in these individuals.

There were several strengths and limitations to our study. The strengths included are as follows: (1) participants with low serum $25(\mathrm{OH}) \mathrm{D}$ were recruited and confirmed with a higher 25(OH)D level following supplementation, and (2) outcomes were based upon objective measurements. The confirmed higher $25(\mathrm{OH}) \mathrm{D}$ level after supplementation permitted the objective assessment of changes in muscle strength, structure, and function as well as postural sway and functional performance from recommended IOM levels of $20-30 \mathrm{ng} / \mathrm{ml}$ to the target levels of $40-50 \mathrm{ng} / \mathrm{ml}$.

The limitations included (1) lack of an independent, randomized, untreated control group and a small sample size $(n=$ 19), with only a single follow-up at 6 months, (2) several different labs were used for serum 25(OH)D testing which incorporated different methods for this assay, and (3) $25(\mathrm{OH}) \mathrm{D}$ supplementation was given with calcium which may have confounded effects. Future larger randomized controlled trial designs should benefit from the data acquired in this study to generate effect sizes for sample size calculations. Short- and/or long-term follow-up changes in response to higher 25(OH)D levels may have been missed at a single 6month follow-up visit. The $20 \%$ loss to follow-up could be minimized in future studies with interim visits over the followup period.

Several different laboratories were used for follow-up serum $25(\mathrm{OH}) \mathrm{D}$ testing which incorporated different methods for this assay. This could have led to an over-estimate or under-estimate in serum $25(\mathrm{OH}) \mathrm{D}$ levels. Specific to this study, it was possible that we included someone in the 20 $30 \mathrm{ng} / \mathrm{ml}$ baseline group or the elevated $40-50 \mathrm{ng} / \mathrm{ml}$ group that was outside of the target range. Future studies should try to standardize serum $25(\mathrm{OH}) \mathrm{D}$ testing to one laboratory, store an additional sample for future testing of each subject at each visit, perform post-hoc standardization analyses based upon standardized reference materials, and, if possible, participate in the CDC lab standardization program for this assay.

Several investigators have established that vitamin $\mathrm{D}_{3}[37$, 38 ] or vitamin $D_{2}$ supplementation along with calcium is more effective in preventing falls as compared with calcium alone. This finding has been contradicted in a study where falls were best predicted by sarcopenia and lean muscle mass [39]. In the setting of sarcopenic obesity, a combination of obesity with low skeletal muscle mass and correction of vitamin D deficiency had a positive role on muscle mass [40].

\section{Conclusions}

The clinical significance of the preliminary findings includes the potential to increase PCSA of the vastus lateralis (muscle structure) and enhance performance while ascending stairs (function) and potentially reducing AP COP excursion and COP path length (measures of balance). Vitamin D supplementation is relatively easy to administer and generally has good compliance due to its well-accepted benefit for managing osteoporosis. Finally, vitamin D supplementation is relatively of low cost which obviates many financial barriers to treatment. The potential for having a relatively low cost means to enhance structure, function, and balance in postmenopausal women that could potentially lower the incidence 
of falls and concomitant fracture makes this area important for further investigation.

The use of vitamin D supplementation to improve muscle structure, muscle strength, balance, and functional task performance remains controversial. The preliminary evidence from this pilot study suggests that it may be possible to augment muscle structure, functional performance, and potentially balance through increasing serum $25(\mathrm{OH}) \mathrm{D}$ to levels between 40 and $50 \mathrm{ng} / \mathrm{ml}$. A clinical trial that incorporates these objective outcome measures with a larger sample size, randomized treatment assignment, and a control group would appear to be warranted.

Acknowledgments The Orthopaedic Chief of Staff Funds were used to conduct this pilot project at HSS

\section{Compliance with ethical standards}

\section{Conflict of interests None.}

Open Access This article is licensed under a Creative Commons Attribution 4.0 International License, which permits use, sharing, adaptation, distribution and reproduction in any medium or format, as long as you give appropriate credit to the original author(s) and the source, provide a link to the Creative Commons licence, and indicate if changes were made. The images or other third party material in this article are included in the article's Creative Commons licence, unless indicated otherwise in a credit line to the material. If material is not included in the article's Creative Commons licence and your intended use is not permitted by statutory regulation or exceeds the permitted use, you will need to obtain permission directly from the copyright holder. To view a copy of this licence, visit http://creativecommons.org/licenses/by/4.0/.

\section{References}

1. Anonymous (2018) Vitamin D - Fact sheet for health professionals. 2018

2. Institute of Medicine (2011) Dietary reference Intakes for calcium and vitamin D. The National Academies Press, Washington, DC

3. Manson JE, Brannon PM, Rosen CJ, Taylor CL (2016) Vitamin D deficiency - is there really a pandemic? N Engl J Med 375:18171820. https://doi.org/10.1056/NEJMp1608005

4. Dam TT, von Muhlen D, Barrett-Connor EL (2009) Sex-specific association of serum vitamin D levels with physical function in older adults. Osteoporos Int 20:751-760

5. Anonymous (2018) Vitamin D Test Kit | DIY At-Home Vitamin D Testing. 2018

6. Holick MF, Matsuoka LY, Wortsman J (1989) Age, vitamin D, and solar ultraviolet radiation. Lancet II:1104-1105

7. Cangussu LM, Nahas-Neto J, Orsatti CL, Bueloni-Dias FN, Nahas EA (2015) Effect of vitamin D supplementation alone on muscle function in postmenopausal women: a randomized, double-blind, placebo-controlled clinical trial. Osteoporos Int 26:2413-2421. https://doi.org/10.1007/s00198-015-3151-9

8. Dhaliwal R, Mikhail M, Usera G, Stolberg A, Islam S, Ragolia L, Aloia JF (2018) The relationship of Physical performance and Osteoporosis prevention with vitamin D in older African Americans (PODA). Contemp Clin Trials 65:39-45
9. Gao LH, Zhu WJ, Liu YJ, Gu JM, Zhang ZL, Wang O, Xing XP, $\mathrm{Xu} \mathrm{L}$ (2015) Physical performance and life quality in postmenopausal women supplemented with vitamin D: a two-year prospective study. Acta Pharmacol Sin 36:1065-1073. https://doi.org/10. 1038/aps.2015.55

10. Akdeniz S, Hepguler S, Ozturk C, Atamaz FC (2016) The relation between vitamin $\mathrm{D}$ and postural balance according to clinical tests and tetrax posturography. J Phys Ther Sci 28:1272-1277. https:// doi.org/10.1589/jpts.28.1272

11. Visser M, Deeg DJ, Lips P, Longitudinal Aging Study Amsterdam (2003) Low vitamin D and high parathyroid hormone levels as determinants of loss of muscle strength and muscle mass (sarcopenia): the Longitudinal Aging Study Amsterdam. J Clin Endocrinol Metab 88:5766-5772

12. Wicherts IS, van Schoor NM, Boeke AJ, Visser M, Deeg DJ, Smit J, Knol DL, Lips P (2007) Vitamin D status predicts physical performance and its decline in older persons. J Clin Endocrinol Metab 92:2058-2065

13. Walrand S (2016) Effect of vitamin D on skeletal muscle. Geriatr Psychol Neuropsychiatr Vieil 14:127-134. https://doi.org/10.1684/ pnv.2016.0599

14. Snijder MB, van Schoor NM, Pluijm SM, van Dam RM, Visser M, Lips P (2006) Vitamin D status in relation to one-year risk of recurrent falling in older men and women. J Clin Endocrinol Metab 91:2980-2985

15. Fielding RA, Travison TG, Kirn DR, Koochek A, Reid KF, von Berens A, Zhu H, Folta SC, Sacheck JM, Nelson ME, Liu CK, Aberg AC, Nydahl M, Lilja M, Gustafsson T, Cederholm T (2017) Effect of structured physical activity and nutritional supplementation on physical function in mobility-limited older adults: Results from the VIVE2 randomized trial. J Nutr Health Aging 21:936-942. https://doi.org/10.1007/s12603-017-0936-x

16. Grimnes G, Emaus N, Cashman KD, Jorde R (2017) The effect of high-dose vitamin D supplementation on muscular function and quality of life in postmenopausal women-A randomized controlled trial. Clin Endocrinol (Oxf) 87:20-28. https://doi.org/10.1111/cen. 13353

17. Murad MH, Elamin KB, Abu Elnour NO, Elamin MB, Alkatib AA, Fatourechi MM, Almandoz JP, Mullan RJ, Lane MA, Liu H, Erwin PJ, Hensrud DD, Montori VM (2011) Clinical review: The effect of vitamin D on falls: a systematic review and meta-analysis. J Clin Endocrinol Metab 96:2997-3006

18. Smith LM, Gallagher JC, Suiter C (2017) Medium doses of daily vitamin D decrease falls and higher doses of daily vitamin D3 increase falls: a randomized clinical trial. J Steroid Biochem Mol Biol 173:317-322

19. Annema W, Nowak A, von Eckardstein A, Saleh L (2018) Evaluation of the new restandardized Abbott Architect 25-OH Vitamin D assay in vitamin D-insufficient and vitamin Dsupplemented individuals. J Clin Lab Anal 32:e22328. https://doi. org $10.1002 /$ jcla. 22328

20. Gerdhem P, Ringsberg KA, Obrant KJ, Akesson K (2005) Association between 25-hydroxy vitamin D levels, physical activity, muscle strength and fractures in the prospective populationbased OPRA Study of Elderly Women. Osteoporos Int 16:14251431

21. Anonymous (1999) European recommendations for surface electromyography: results of the SENIAM project. Roessingh Research and Development B.V., Enschede

22. Hassani A, Patikas D, Bassa E, Hatzikotoulas K, Kellis E, Kotzamanidis C (2006) Agonist and antagonist muscle activation during maximal and submaximal isokinetic fatigue tests of the knee extensors. J Electromyogr Kinesiol 16:661-668

23. Barber L, Barrett R, Lichtwark G (2009) Validation of a freehand 3D ultrasound system for morphological measures of the medial 
gastrocnemius muscle. J Biomech 42:1313-1319. https://doi.org/ 10.1016/j.jbiomech.2009.03.005

24. Iolascon G, de Sire A, Calafiore D, Moretti A, Gimigliano R, Gimigliano F (2015) Hypovitaminosis D is associated with a reduction in upper and lower limb muscle strength and physical performance in post-menopausal women: a retrospective study. Aging Clin Exp Res 27(Suppl 1):23. https://doi.org/10.1007/s40520-0150405-5

25. Mathei C, Van Pottelbergh G, Vaes B, Adriaensen W, Gruson D, Degryse JM (2013) No relation between vitamin D status and physical performance in the oldest old: results from the Belfrail study. Age Ageing 42:186-190. https://doi.org/10.1093/ageing/afs186

26. Rosendahl-Riise H, Spielau U, Ranhoff AH, Gudbrandsen OA, Dierkes J (2017) Vitamin D supplementation and its influence on muscle strength and mobility in community-dwelling older persons: a systematic review and meta-analysis. J Hum Nutr Diet 30: 3-15. https://doi.org/10.1111/jhn.12394

27. Anek A, Bunyaratavej N, Jittivilai T (2015) Effects of short-term vitamin D supplementation on musculoskeletal and body balance for prevention of falling in postmenopausal women. J Med Assoc Thai 98(Suppl 8):26

28. Saito K, Miyakoshi N, Matsunaga T, Hongo M, Kasukawa Y, Shimada Y (2016) Eldecalcitol improves muscle strength and dynamic balance in postmenopausal women with osteoporosis: an open-label randomized controlled study. J Bone Miner Metab 34: 547-554. https://doi.org/10.1007/s00774-015-0695-x

29. Dhesi JK, Bearne LM, Moniz C, Hurley MV, Jackson SH, Swift CG, Allain TJ (2002) Neuromuscular and psychomotor function in elderly subjects who fall and the relationship with vitamin D status. J Bone Miner Res 17:891-897

30. LeBoff MS, Hawkes WG, Glowacki J, Yu-Yahiro J, Hurwitz S, Magaziner J (2008) Vitamin D-deficiency and post-fracture changes in lower extremity function and falls in women with hip fractures. Osteoporos Int 19:1283-1290

31. Suzuki T, Kwon J, Kim H, Shimada H, Yoshida Y, Iwasa H, Yoshida H (2008) Low serum 25-hydroxyvitamin D levels associated with falls among Japanese community-dwelling elderly. J Bone Miner Res 23:1309-1317

32. Dhesi JK, Jackson SH, Bearne LM, Moniz C, Hurley MV, Swift CG, Allain TJ (2004) Vitamin D supplementation improves neuromuscular function in older people who fall. Age Ageing 33:589595
33. Bischoff-Ferrari HA, Dietrich T, Orav EJ, Hu FB, Zhang Y, Karlson EW, Dawson-Hughes B (2004) Higher 25hydroxyvitamin D concentrations are associated with better lower-extremity function in both active and inactive persons aged $>$ or $=60 \mathrm{y}$. Am J Clin Nutr 80:752-758

34. Kuchuk NO, Pluijm SM, van Schoor NM, Looman CW, Smit JH, Lips P (2009) Relationships of serum 25-hydroxyvitamin D to bone mineral density and serum parathyroid hormone and markers of bone turnover in older persons. J Clin Endocrinol Metab 94: $1244-1250$

35. Shardell M, Hicks GE, Miller RR, Kritchevsky S, Andersen D, Bandinelli S, Cherubini A, Ferrucci L (2009) Association of low vitamin D levels with the frailty syndrome in men and women. J Gerontol A Biol Sci Med Sci 64:69-75

36. Bischoff-Ferrari HA, Dawson-Hughes B, Willett WC, Staehelin HB, Bazemore MG, Zee RY, Wong JB (2004) Effect of Vitamin D on falls: a meta-analysis. JAMA 291:1999-2006

37. Pfeifer M, Begerow B, Minne HW, Abrams C, Nachtigall D, Hansen C (2000) Effects of a short-term vitamin D and calcium supplementation on body sway and secondary hyperparathyroidism in elderly women. J Bone Miner Res 15:1113-1118

38. Bischoff HA, Stahelin HB, Dick W, Akos R, Knecht M, Salis C, Nebiker M, Theiler R, Pfeifer M, Begerow B, Lew RA, Conzelmann M (2003) Effects of vitamin D and calcium supplementation on falls: a randomized controlled trial. J Bone Miner Res 18:343-351

39. Bischoff-Ferrari HA, Orav JE, Kanis JA, Rizzoli R, Schlogl M, Staehelin HB, Willett WC, Dawson-Hughes B (2015) Comparative performance of current definitions of sarcopenia against the prospective incidence of falls among communitydwelling seniors age 65 and older. Osteoporos Int 26:2793-2802. https://doi.org/10.1007/s00198-015-3194-y

40. Petroni ML, Caletti MT, Dalle Grave R, Bazzocchi A, Aparisi Gomez MP, Marchesini G (2019) Prevention and treatment of sarcopenic obesity in women. Nutrients 11 . https://doi.org/10. 3390/nu11061302

Publisher's note Springer Nature remains neutral with regard to jurisdictional claims in published maps and institutional affiliations. 